\title{
Extensão rural e construção da equidade de gênero: limites e possibilidades
}

\author{
Rural extension and construction of gender equity: limits and possibilities
}

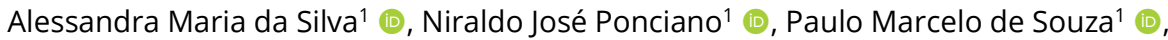 \\ Lilian Sagio Cezar ${ }^{1}$ (D) \\ ${ }^{1}$ Universidade Estadual do Norte Fluminense Darcy Ribeiro (UENF), Campos dos Goytacazes (RJ), Brasil. E-mails: \\ alessandravet92@gmail.com; njponciano@uenf.br; pmsouza@uenf.br; Isagio@hotmail.com
}

Como citar: Silva, A. M., Ponciano, N. J., Souza, P. M., \& Cezar, L. S. (2020). Extensão rural e construção da equidade de gênero: limites e possibilidades. Revista de Economia e Sociologia Rural, 58(1), e187845.

https://doi.org/10.1590/1806-9479.2020.187845

\begin{abstract}
Resumo: A extensão rural no Brasil privilegiou a difusão tecnológica de práticas intensivas de produção, ampliando as desigualdades socioeconômicas no meio rural, especialmente as relacionadas a gênero. Com a instituição da Política Nacional de Assistência Técnica e Extensão Rural (Pnater), a Extensão Rural passou a atender aos princípios de equidade de gênero previstos para atuação extensionista. Este trabalho teve por objetivo compreender como os extensionistas rurais do órgão oficial de Assistência Técnica e Extensão Rural (Ater) do Espírito Santo entendem o seu papel na contribuição para a construção da equidade de gênero na agricultura familiar nos municípios de Linhares, Rio Bananal e Sooretama. Para tanto, aplicaram-se roteiros de entrevistas semiestruturadas para dez agentes de extensão em desenvolvimento rural, servidores da instituição oficial de Ater daqueles municípios. Os dados foram transcritos, sistematizados e submetidos à análise de conteúdo. Os extensionistas apresentaram-se naturalizados com as desigualdades de gênero, não desenvolvendo ações que incentivam a participação feminina nas políticas públicas. Mudanças nos paradigmas de gênero arraigados à extensão rural devem ser estimuladas, tanto na academia quanto nas instituições de Ater, com o propósito de se efetivar a participação feminina nas políticas públicas para a agricultura familiar.
\end{abstract}

Palavras-chaves: Assistência Técnica e Extensão Rural, mulheres rurais, Pnater, relações de gênero.

Abstract: Rural extension in Brazil has favored the technological diffusion of intensive production practices, increasing socioeconomic inequalities in the rural environment, especially those related to gender. Due to the institution of the National Policy of Technical Assistance and Rural Extension (Pnater), the rural extension began to comply with the principles of gender equality for extension work. The objective of this work was to understand how rural extensionists of the official Technical Assistance and Rural Extension Agency of Espírito Santo, Brazil, understand their role in contributing to the construction of gender equity in family agriculture in the municipalities of Linhares, Rio Bananal and Sooretama. For that purpose, semi-structured interviews were issued to ten extension agents of the official institution of those municipalities. The data were transcribed, systematized and submitted to content analysis. Extension workers were naturalized with gender inequalities and did not develop actions that encourage female participation in public policies. Changes in the gender paradigms rooted in the rural extension should be stimulated both in the academy and in rural extension institutions aiming to implement the women participation in public policies for family agriculture.

Keywords: Technical Assistance and Rural Extension, rural women, Pnater, gender relationships.

\section{Introdução}

A ação extensionista rural foi, durante muitos anos, caracterizada por uma assistência técnica de visão difusionista e produtivista, resultando na adoção de pacotes tecnológicos e na utilização de práticas intensivas de produção que contribuíram para a degradação do meio ambiente e para o crescimento das desigualdades socioeconômicas no meio rural. E em 
relação às questões de gênero, a extensão rural contribuiu para a segregação das funções no espaço rural ao não favorecer o acesso ao conhecimento técnico-gerencial, assim como o desenvolvimento das capacidades das agricultoras enquanto sujeito produtivo na unidade familiar agrícola, mantendo a visibilidade do trabalho feminino exclusivamente para as atividades domésticas. Nas diversas formas organizativas, também foi privilegiada a atuação masculina e essa hegemonia em todos os espaços de decisão contribuiu para ampliar o quadro de desigualdade de gênero.

Em contraposição ao modelo difusionista que se destacou no período de 1970 a 1990 e atendendo às reivindicações dos movimentos dos agricultores e agricultoras familiares, a Política Nacional de Assistência Técnica e Extensão Rural para a Agricultura Familiar e Reforma Agrária (Pnater), elaborada em 2003 e instituída pela Lei n. 12.188 de 11 de janeiro de 2010 (Brasil, 2010), propôs uma nova visão de desenvolvimento rural em busca de um modelo menos desigual e excludente. A construção de novas relações entre os diferentes sujeitos no desenvolvimento rural proposta pela Pnater procurou dar maior visibilidade ao trabalho da mulher e sua participação em todos os espaços produtivos e sociais, na tentativa de reduzir as desigualdades de gênero enraizadas na sociedade, orientando, dessa forma, a ação extensionista em todo o território nacional.

No estado do Espírito Santo, a Assistência Técnica e Extensão Rural (Ater) é executada pela autarquia estadual denominada Instituto Capixaba de Pesquisa, Assistência Técnica e Extensão Rural (Incaper), que tem escritórios em todos os municípios do estado, além de 11 fazendas experimentais, onde se desenvolvem pesquisas agropecuárias. Fazem parte do quadro de agentes de extensão em desenvolvimento rural do instituto 268 extensionistas rurais, que desenvolvem ações orientadas para o desenvolvimento rural com redução das desigualdades sociais (Oliveira \& Borges, 2016).

A partir do contexto apresentado e sob a égide da Pnater, questiona-se: a extensão rural oficial tem incentivado ou fortalecido a participação das mulheres rurais no estado do Espírito Santo? A concepção dos agentes de extensão quanto às relações de gênero no espaço rural tem contribuído para a sua postura nas ações extensionistas? É possível que, com base no princípio de equidade de gênero proposto pela Pnater, os extensionistas rurais estejam efetivamente preparados para a atuação na Ater para a agricultura familiar, incentivando e fortalecendo a inclusão e participação das mulheres rurais em suas ações.

Este trabalho teve por objetivo compreender como os extensionistas rurais do órgão oficial de Ater do Espírito Santo entendem o seu papel na contribuição para a construção da equidade de gênero na agricultura familiar nos municípios de Linhares, Rio Bananal e Sooretama.

\section{Revisão literária}

\subsection{As relações de gênero na agricultura familiar}

A agricultura familiar corresponde à uma forma de organização da produção em que propriedade e trabalho estão estreitamente ligados à família, a qual é a proprietária dos meios de produção e também quem realiza o trabalho na propriedade. Nela ocorrem não somente a transmissão do patrimônio, mas também da cultura e dos valores utilizados nas estratégias de reprodução da exploração (Lamarche, 1993; Wanderley, 2001).

O conceito de agricultura familiar deixa claro que a execução dos trabalhos e a gestão da propriedade são realizados pela família, como uma unidade. No entanto, em sua forma de organização, a divisão dos trabalhos está diretamente relacionada às relações de gênero e de geração. Não se trata de uma unidade homogênea, mas de uma organização em que seus componentes apresentam suas individualidades e onde ocorrem conflitos a partir dessas relações (Siliprandi \& Cintrão, 2015).

As relações de gênero e de geração definem a divisão de trabalho nas famílias rurais e, a partir desta, as relações de poder (Scott et al., 2010). Diante dessa afirmação, torna-se importante destacar que o conceito de identidade sexual é etimologicamente diferente do conceito de gênero. Enquanto a identidade sexual se refere às características físicas e 
biológicas do indivíduo, a identidade de gênero se refere à construção social do que é ser feminino e masculino (Beauvoir, 1949; Belotti, 1987; Scott, 2008).

O termo gênero tem origem na percepção cultural sobre as diferenças sexuais, uma construção social orientada em função das características biológicas, que moldam o comportamento das pessoas baseado nessas diferenças e sobre elas estabelecem-se as relações de poder (Beauvoir, 1949; Piscitelli, 2009). E é baseado nesta construção social de gênero que se constrói a divisão sexual do trabalho, enfatizando as diferenças entre homens e mulheres, como produção e reprodução, público e privado (Bourdieu, 2002; Farah, 2004) e a divisão social e cultural na perspectiva da hierarquia nas relações de poder entre homens e mulheres em contextos específicos (Scott, 2008).

A partir da construção social das relações de gênero, as divisões dos papéis sociais se naturalizam por meio da construção de valores, comportamentos e símbolos que impõem uma condição desigual e desprivilegiada da mulher em relação ao homem (Bourdieu, 2002; Hernández, 2009). Existe uma normalização na distribuição das tarefas no espaço rural, cabendo às mulheres as atividades domésticas e reprodutivas e aos homens as atividades financeiras e produtivas. Ocorre uma exclusão da mulher no conhecimento das tecnologias agropecuárias e da sua participação nas decisões, as quais são atribuídas ao marido, além da desvalorização do seu trabalho, o qual é considerado como uma "ajuda" sem direito à remuneração (Siliprandi, 2015).

Esse não reconhecimento do trabalho da mulher nos espaços de seu domínio, como hortas, cultivos medicinais, criação de pequenos animais etc., torna-o invisível para a economia formal, quando, na verdade, cumprem funções de valor inestimável (Siliprandi, 2009). Essas funções são importantes para a segurança alimentar, para a complementação de renda da família e como estratégias de conservação da biodiversidade (Pacheco, 2009).

Assim, as mulheres são as mais penalizadas no contexto de produção caracterizado por escassez de oportunidade de trabalho e de renda. Para Figueiredo (2010), o desenvolvimento local estaria incompleto se não se considerar a perspectiva da emancipação das mulheres agricultoras, com vistas a relações sociais mais equitativas.

A participação feminina em uma sociedade de raízes machistas é uma luta social (Figueiredo, 2010). A emancipação feminina depende da reivindicação de sua cidadania, ou seja, dos direitos das mulheres previstos em lei e dos benefícios concedidos pelas políticas públicas. Essa reivindicação tem sido sustentada pela luta feminista do campo, a qual, a partir do feminismo como ciência e como movimento social, tem apresentado papel primordial na conquista dos direitos das mulheres e para sua emancipação como sujeito político e de direitos.

O feminismo, como ciência, não se resume em uma única teoria, mas em diversas construções que partem do mesmo princípio: questionar o modelo social que sustenta a desigualdade. Ele tem o propósito de compreender como as relações de gênero se configuram em relações de poder político entre homens e mulheres. O feminismo, como movimento social e político, reivindica a liberdade e autonomia para as mulheres; questiona a estrutura social que construiu sua base na exploração, dominação e violência contra os seres humanos. Contribui para as transformações política, social e cultural para uma sociedade mais igualitária a partir do processo educativo de tomada da consciência das desigualdades de gênero, raça e classe (Jalil, 2009).

A partir da luta feminista no campo, políticas públicas, programas e projetos de incentivo ao acesso e de garantia dos direitos foram implementados nos últimos anos. São políticas que garantem os direitos e o acesso à documentação, à terra, ao crédito, à organização produtiva, à produção, transformação e comercialização, aos serviços de assistência técnica e extensão rural, à participação na gestão, ao resgate cultural e dos conhecimentos tradicionais. A inclusão das mulheres como beneficiárias diretas das políticas públicas ocorreu a partir do reconhecimento social e político do seu protagonismo na agricultura familiar e da necessidade de sua autonomia econômica (Siliprandi \& Cintrão, 2015).

No entanto, as transformações política, social e cultural da sociedade somente serão possíveis se houver mudanças nas relações hierárquicas e opressoras da esfera pública (Moraes et al., 2018). E aqui se enquadra a extensão rural como política pública e como contribuição do Estado no processo para o desenvolvimento rural sustentável. 


\subsection{A extensão rural no Brasil - da Ater tradicional à Ater feminista}

A extensão rural no Brasil se apresentou como um projeto político vinculado ao contexto socioeconômico que se modificou conforme as ideologias e os interesses dos segmentos sociais em seus espaços conquistados na agenda política (Monteiro, 2008; Coelho, 2016). Cabe aqui, portanto, compreender cada um desses contextos que contribuíram para a construção da Ater atual, dando destaque às questões de gênero.

O conceito de extensão rural foi moldado com o tempo e de acordo com os contextos socioeconômicos e, especialmente, políticos, mas se baseou na ideia de processo educativo não formal para os indivíduos do campo (Peixoto, 2008). A influência na extensão rural brasileira se deu baseada na americana, predominando a corrente da "escola nova" que utilizava como slogan "aprender a fazer, fazendo". (Oliveira, 1988)

Oliveira (1988) entende extensão rural como sendo um processo educativo que tem por finalidade promover a adoção de novas tecnologias pelos agricultores, que resultem no aumento da produção, produtividade e renda - um conceito tradicional e conservador. Ao encontro da mesma orientação, Olinger (1996) complementa que a extensão rural é um processo educativo em que o sujeito de sua ação é o ser humano e os objetivos principais são a produção e a comercialização das safras com menor dano possível ao meio ambiente.

Paulo Freire (1983) teceu severas críticas ao uso do termo "extensão", pois, segundo ele, o sentido etimológico da palavra está ligado à ideia de "estender algo a alguém", de transmitir, doar, entregar, manipular. Esses termos envolvem ações que transformam os seres humanos em coisas, negando sua capacidade de interação e de transformação do mundo. Para Freire (1983), o extensionista, antes de tudo, deve ser um educador, o qual também se educa em uma troca de conhecimentos. Deve ser um agente que, em suas relações homem-mundo, seja capaz de transformações reais e radicais. Freire (1983) propõe a dialogicidade na extensão rural, não a difusão ou transferência de conhecimento de uma pessoa "detentora do saber" para outra pessoa "desprovida do saber", pois ambas possuem saberes diferentes.

Assim, Caporal (2003) propõe um conceito mais abrangente da extensão rural no contexto da Pnater - e em consonância com as ideias de Freire - como sendo um processo educativo e transformador que se baseia na participação e na construção social de conhecimentos, na consciência sobre a realidade, em busca do desenvolvimento sócio-econômico-ambiental equitativo e sustentável, com base em princípios agroecológicos e culturais dos atores sociais envolvidos no processo.

E, finalmente, o primeiro inciso do artigo $2^{\circ}$, referente ao Capítulo1, que trata da Pnater, entende-se por Ater:

Serviço de educação não formal, de caráter continuado, no meio rural, que promove processos de gestão, produção, beneficiamento e comercialização das atividades e dos serviços agropecuários e não agropecuários, inclusive das atividades agroextrativistas, florestais e artesanais (Brasil, 2010).

Dessa forma, a história da atuação da extensão rural no Brasil se iniciou de forma intervencionista com vistas ao desenvolvimento rural vinculado à ideia de modernização e ao seu financiamento via crédito rural (Coelho, 2016). Rodrigues (1997) propôs uma divisão cronológica das fases da extensão rural no Brasil, durante o período que abrangeu o final da década de 1940 até o final de 1980, as quais seriam: Humanismo Assistencialista, Difusionista Produtivista, Humanismo Crítico. Tais fases estariam relacionadas às mudanças dos planos e programas de governo e às regras das instituições de Ater em cada época (Coelho, 2016; Faleiro Barros, 2016; Rodrigues, 1997).

Conforme citado por Rodrigues (1997), a fase do Humanismo Assistencialista deu início à extensão rural no Brasil e teve por objetivo a melhoria da qualidade de vida das famílias rurais. Foram criadas as Associações de Crédito e Assistência Rural (Acar), sendo a primeira implementada em Minas Gerais em 1948. Nesta fase, que se estendeu até 1962, a extensão rural buscava aplicar o modelo americano do "aprender a fazer, fazendo" e envolvia uma equipe básica formada por um engenheiro agrônomo, uma economista doméstica e uma secretária e era uma forma de legitimar a presença no Estado no meio rural. É importante destacar que, com esta composição da equipe de Ater, a extensão rural já se orientava pela 
divisão sexual do trabalho no campo, pois os engenheiros agrônomos buscavam o atendimento ao público masculino com vistas à produção econômica e as economistas domésticas orientavam o público feminino para o cuidado da família, da casa e do entorno (Olinger, 1996). Embora o público-alvo da extensão rural da época fosse a família agricultora, somente os homens "chefes de família" eram considerados agricultores, evidenciando a visão patriarcal do Estado e da sociedade. Mulheres e jovens formavam uma categoria em separado, com atendimento exclusivo e atividades restritas. Às mulheres, era negado o acesso às tecnologias produtivas e à participação política e econômica.

Na segunda fase proposta por Rodrigues (1997), iniciada em 1963, observou-se a mudança do perfil das ações extensionistas que deixou de se orientar pelo bem-estar das famílias para priorizar a produção e produtividade, caracterizando a fase de Difusionismo Produtivista. Neste momento, o Estado passou a intervir mais intensamente no meio rural, com o objetivo de modernizar - no sentido de utilizar a mecanização e insumos agroquímicos e genéticos - o setor agrícola. A metodologia da extensão rural passa a ser de difusão de pacotes tecnológicos adotados via financiamento pelo crédito orientado. As mulheres, antes atendidas em seus espaços domésticos, se tornaram ainda mais invisíveis aos olhos da extensão rural, voltada, agora, para a atividade econômica da propriedade rural - espaço masculino na sociedade patriarcal.

Conforme citado por Rodrigues (1997), com a grande crise econômica da década de 1980, a estratégia Difusionista Produtivista da extensão rural foi colocada em xeque. Iniciouse a fase denominada Humanismo Crítico, em que os ideários da extensão rural se voltavam para a participação democrática e problematizadora, sem a presença intervencionista impositora do Estado, tendo os agricultores como sujeitos de direitos, porém, sem o paternalismo identificado pelo autor na primeira fase Humanista Assistencialista. A função da extensão rural seria de mobilização e mediação, não mais manipuladora, seguindo os propósitos da educação libertadora freiriana. No entanto, os esforços da extensão rural para uma guinada nas ações de Ater em um novo modelo mais participativo não lograram resultados positivos até a década de 1990, embora tenha traçado fundamentos que contribuíram para a construção da Pnater (Nunes et al., 2013). O longo período de ditadura vivenciado pelo serviço de extensão rural que impunha a ação difusionista produtivista resultou em uma naturalização no comportamento organizacional para muitos técnicos de Ater. E, segundo Peixoto (2008), o ideário neoliberal da década de 1980 contribuiu para a decadência do serviço público de Ater, pois estes serviços, assim como outros, foram considerados prescindíveis e, portanto, de responsabilidade privada. Assim, culminou-se com a extinção da Embrater durante o Governo Collor, em 1990, passando a responsabilidade para os estados e municípios a manutenção ou não dos serviços públicos de Ater.

É importante ressaltar que, durante o período citado, desde a implantação da extensão rural no Brasil, não houve a preocupação da dissolução da desigualdade de gênero no espaço rural brasileiro. A participação feminina sempre esteve à margem das mudanças sociais e políticas ocorridas durante décadas. No entanto, a partir da década de 1990, movimentos sociais passaram a pressionar o governo pela implementação de políticas públicas que garantissem o acesso à terra, crédito, mercado, dentre outras reivindicações. Paralelamente, movimentos feministas do campo, como as Marchas das Margaridas - que reúnem mulheres rurais de todo o Brasil desde o ano de 2000 - e também as Conferências Nacionais de Políticas para as Mulheres, passaram a reivindicar os direitos das mulheres rurais, a garantia de acesso aos serviços e políticas públicas pelas mulheres e sua família e a emancipação econômicopolítica feminina (Cintrão \& Siliprandi, 2011).

Com a continuidade dos movimentos reivindicatórios do campo, com as mudanças institucionais e com os novos contextos políticos que priorizaram a participação, os extensionistas necessitaram se adequar à sua realidade de atuação, conforme as exigências das políticas públicas do início deste século. Deu-se, portanto, o início da segunda fase do Humanismo Crítico, conforme proposto por Nunes et al. (2013). Tais autores consideram que a segunda fase do Humanismo Crítico envolveu a participação social na conquista de direitos e a construção de uma extensão rural voltada para a participação e para a agroecologia, na qual o extensionista rural deveria apresentar uma atuação mediadora de conflitos e de elo entre as políticas públicas e o público-alvo - a família rural. 
Dessa forma, as conquistas dos movimentos sociais no âmbito político resultaram na elaboração da Pnater, em 2003, instituída como política pela Lei n. 12.188 de 11 de janeiro de 2010. A Pnater apresenta como principais diretrizes a adoção de metodologias participativas pela extensão rural; a adoção de práticas de base ecológica; a contribuição para o desenvolvimento rural sustentável; a equidade nas relações de gênero, geração, raça e etnia; a contribuição para a segurança e soberania alimentar e nutricional (Brasil, 2010).

Diante desse contexto, diversas políticas públicas voltadas para o meio rural buscaram mudar o cenário rural hegemonicamente masculino, como a criação de linhas de crédito especificamente para as mulheres da agricultura familiar, apoio à comercialização, fomento às atividades produtivas rurais, incentivo à organização de mulheres, dentre outras, as quais têm não somente incentivado a participação da mulher, como também determinado quantitativamente esta participação nas metas institucionais (Filipak, 2017). Embora essas políticas públicas não sejam, em sua maioria, destinadas às mulheres rurais, estabeleceram-se cotas de participação feminina. No entanto, essas cotas de participação apresentam caráter orientativo e não de controle da participação. Ou seja, a atuação dos movimentos sociais e da extensão rural como forma de garantir ou favorecer o acesso das mulheres às políticas públicas tornou-se necessária na mediação desse acesso (Cintrão \& Siliprandi, 2011).

No estado do Espírito Santo, a trajetória da extensão rural se iniciou com a Agência de Crédito e Assistência Rural do Espírito Santo (Acares) em 1956, tonando-se Emater-ES em 1975 (Duarte, 2010). De acordo com Duarte (2010), a extensão rural do Espírito Santo seguiu a tendência nacional das fases de Humanismo Assistencialista e de Difusionismo Produtivista, e, a partir de 1985, submetendo-se às pressões externas na fase de Humanismo Crítico, buscou mudanças na sua forma de atuação visando a educação na extensão rural. Embora as mudanças no processo da extensão rural no Espírito Santo nesta fase do Humanismo Crítico tenham resultado em ações mais participativas e com foco na família, o extensionista rural permaneceu com a postura de "fonte" de conhecimento e com ação fragmentada (Duarte, 2012).

Em 1999, ocorreu a fusão da instituição estadual de pesquisa, a Empresa Capixaba de Pesquisa Agropecuária (Emcapa) com a Emater, resultando na criação da Empresa Capixaba de Pesquisa, Assistência Técnica e Extensão Rural (Emcaper), objetivando a otimização de esforços, em uma ação articulada entre pesquisa e extensão, para atender um maior número de produtores. Posteriormente, em 2000, se tornou uma autarquia, adotando o nome de Instituto Capixaba de Pesquisa, Assistência Técnica e Extensão Rural (Incaper) (Fassio \& Castro, 2006). Conforme citado por Duarte (2010), paralelamente à criação do Incaper, houve mudança na missão do instituto que definiu como público prioritário a agricultura de base familiar e a adoção do modelo de desenvolvimento rural sustentável, com ações participativas, seguindo as mudanças em curso no Brasil.

A Pnater, segundo Duarte (2012), encontrou um cenário favorável a mudanças no estado do Espírito Santo, pois em 2005 e em 2012 houve contratação de servidores efetivos para a extensão rural, via concurso público, que deveriam apresentar o perfil para uma extensão rural diferenciada. Os "novos" extensionistas rurais passaram pelo processo de capacitação sobre os princípios da Pnater. E, conforme apresentado por Oliveira \& Borges (2016), os técnicos do instituto têm apresentado resultados em ações que visam a redução das desigualdades sociais e, dentre elas, as de gênero.

De fato, para atender às mudanças propostas pela Pnater, o documento elaborado em 2003 já apontava a necessidade da capacitação continuada e massiva dos agentes de Ater, responsáveis pela execução da transição para a "nova Ater" proposta, para garantir a implantação de um serviço "baseado em processos educativos potencializadores do crescimento do ser humano como cidadão" (Brasil, 2004, p. 21). No entanto, Faleiro Barros (2016) considera que a Pnater, por ser baseada em princípios que vão de encontro com a extensão convencional tão enraizada nas organizações estatais, ainda enfrenta vários desafios em sua implementação, como a formação acadêmica e continuada dos extensionistas, a dificuldade da gestão organizacional condizente com a política, dificuldades institucionais, entre outros. 
Jalil et al. (2017) reconhecem que, com as novas exigências metodológicas e políticas propostas pela Pnater, houve, inicialmente, uma resistência por parte das instituições e técnicos, presos à forma de fazer Ater ainda centrada na família, representada por seu "chefe", e voltada para a produção. Mas, a partir de 2003, houve também avanços na discussão intersetorial de gênero proposta pelo Plano Nacional de Políticas para as Mulheres I e II, que, dentre outras diretrizes, propuseram o acesso das mulheres rurais aos serviços de Ater, como forma de contribuir para a sua inclusão econômica. Reconhece-se, portanto, uma sensibilização para o tema, resultando na criação de Chamadas Públicas de Ater para atendimento exclusivo para as mulheres rurais. A região Nordeste foi a mais beneficiada com tais chamadas públicas. O estado do Espírito Santo não foi contemplado.

Em algumas regiões onde foram executadas as chamadas públicas de Ater para as mulheres, foi incorporada a perspectiva feminista nas práticas metodológicas de campo, envolvendo questões políticas, econômicas, sociais, produtivas e culturais. No entanto, segundo Jalil et al. (2017), houve uma necessidade de se superar os preconceitos e qualificar as organizações na formação feminista, reconhecendo a existência de um espaço patriarcal opressor e a necessidade de se desenvolver um trabalho emancipador para a mulher rural, despertando nelas e na sociedade seu papel como sujeito político. Assim, em consonância com a própria Pnater, Santos (2017) e Moraes et al. (2018) propuseram como forma de atuação extensionista para a redução das desigualdades de gênero no meio rural a adoção de uma pedagogia feminista nessa nova visão da Ater.

A pedagogia feminista está relacionada à educação para a libertação, assim como proposto por Freire (1983), mas com enfoque em estratégias que ressaltem a consciência das mulheres para o diálogo sobre seus direitos e sobre seu lugar na sociedade. A educação proposta tem como alguns dos propósitos a problematização, o questionamento e a modificação das práticas e representações sociais impostas pela sociedade, os quais se caracterizam como patriarcais, capitalistas e fundamentalistas, e que invisibilizam, oprimem e reprimem as reações e atitudes das mulheres. Assim, a pedagogia feminista utiliza de estratégias, métodos e ferramentas coletivas que apontem para a construção de relações sociais emancipatórias, visando a autonomia das mulheres (Korol, 2007).

A partir da pedagogia feminista constrói-se, então, a Ater feminista, que diz respeito às ações extensionistas que aplicam metodologias e estratégias com o propósito de romper com a lógica difusionista, hierarquizada e androcêntrica, reconhecendo, potencializando e valorizando a troca de saberes, histórias e vozes das mulheres rurais a partir de suas realidades, bem como romper com as desigualdades de gênero e contribuir para a emancipação das mulheres para o desenvolvimento de sua autonomia (Moraes et al., 2018).

Essa "nova forma de fazer" a Ater (Moraes et al., 2018, p. 9) com um olhar feminista exige o desenvolvimento de novos saberes pelos extensionistas, além da desconstrução dos paradigmas androcêntricos arraigados aos saberes acadêmico e prático que permeiam a extensão rural brasileira. A abordagem para esses novos conhecimentos deve partir de questões como: a divisão sexual do trabalho, rompendo com os padrões estabelecidos que restringem o espaço privado às mulheres e estendem o espaço público aos homens; o direito da mulher de gerar, acessar e gerir a renda da propriedade, dentre outros. Deve refletir e questionar as políticas públicas a partir de um olhar feminista, contribuindo para sua reformulação, implementação e efetividade. Há, portanto, a necessidade da formação política e feminista dos agentes de Ater, como forma de influenciar na sua concepção de mundo e, consequentemente, em suas ações, contribuindo para promover a transformação social e reflexiva dos agentes promotores da mudança (Moraes et al., 2018).

Portanto, a partir do contexto da Pnater e das proposições das autoras feministas, a Ater se destaca como uma importante ferramenta de fortalecimento da atuação das mulheres no espaço rural. Mas, para tanto, é necessário que a formação dos agentes de extensão seja feita de uma forma crítica e que seja vivenciada na prática. Há a necessidade de se romper com a visão androcêntrica e dominante, naturalizada sobre a hierarquia de gêneros associada à divisão sexual do trabalho existente nas famílias rurais, especialmente. (Villwock et al., 2016) 


\section{Metodologia}

A pesquisa empírica, do tipo qualitativa, foi realizada entre outubro de 2016 e fevereiro de 2017. O recorte geográfico da pesquisa corresponde aos municípios de Linhares, Rio Bananal e Sooretama, pertencentes à microrregião administrativa Rio Doce, localizada na região central do estado.

Como unidades de análise, todos os dez extensionistas rurais do órgão estadual de Ater que atuam nos municípios relacionados participaram da pesquisa, submetendo-se à aplicação de um roteiro de entrevista semiestruturada composta por perguntas que abordaram: a formação acadêmica e a formação continuada e sua relação com o conhecimento dos conceitos de gênero e extensão rural; o conhecimento sobre a Pnater; as experiências dos extensionistas na implementação de políticas públicas com ações afirmativas de gênero; a percepção das relações de gênero nas famílias rurais a partir da visão dos extensionistas; as perspectivas de mudanças para a redução das desigualdades de gênero na visão dos extensionistas; a percepção dos extensionistas quanto ao seu papel nesse processo de mudança.

As entrevistas foram gravadas e posteriormente transcritas e codificadas. Cada extensionista recebeu uma codificação com as iniciais ER (extensionista rural) seguidas de numeral que representou a ordem em que foram entrevistados, variando de ER1 a ER10. Os dados obtidos foram sistematizados, categorizados e submetidos à análise de conteúdo (Bardin, 1977).

Assim, a partir das categorias, os resultados foram organizados e apresentados de forma a discutir: o conhecimento dos extensionistas sobre extensão rural e gênero a partir da sua formação acadêmica e continuada, especialmente em relação aos princípios da Pnater; o ponto de vista dos entrevistados diante das relações de gênero vivenciadas na prática extensionista; a posição dos extensionistas quanto ao papel da extensão rural no processo de mudança dos paradigmas sociais.

\section{Resultados e discussão}

\subsection{Extensão rural e gênero: do conceito à prática extensionista}

Os extensionistas rurais submetidos à entrevista formam o quadro técnico efetivo do órgão de Ater da microrregião Rio Doce. Dos dez extensionistas entrevistados, três são mulheres. Quanto à formação acadêmica, todos têm formação na área de ciências agrárias, sendo oito com graduação em nível superior (Agronomia, Ciências Agrárias, Engenharia Florestal, Tecnologia em Silvicultura e Zootecnia) e dois de nível médio técnico em agropecuária. A maior parte dos entrevistados (60\%) tiveram sua formação acadêmica anterior à institucionalização da Pnater.

A experiência dos entrevistados como extensionistas rurais teve média de 11,2 anos, variando de três a 23 de atuação na área, seja ela no serviço oficial estadual, municipal, em movimentos sociais ou organizações não governamentais. A maior parte dos extensionistas (seis) teve o primeiro contato com a extensão rural a partir do ingresso como servidor público no instituto estadual de Ater. Quatro dos dez entrevistados atuaram como extensionistas rurais ligados a movimentos sociais, como o Movimento de Educação Promocional do Estado do Espírito Santo (Mepes) e a Assessoria e Serviços a Projetos em Agricultura Alternativa (AS-PTA), ou como servidores municipais em Secretarias de Agricultura, anteriormente ao ingresso no instituto estadual de Ater. O tempo médio de serviço oficial no órgão estadual de Ater foi de 7,6 anos, variando de três a 12 anos, sendo que seis deles atuam há mais de 10 anos na Ater oficial.

Independentemente da formação acadêmica, todos afirmaram não ter recebido preparação suficientemente para atuação em extensão rural, tendo "aprendido na prática" (ER 10) o seu modus operandi. Todos afirmaram também que não houve qualquer tipo de treinamento ou orientação para o trabalho com questões de gênero, seja durante a formação acadêmica ou na formação continuada oferecida pela instituição de trabalho. 
A formação acadêmica é técnica, ela não prepara para isso, né? Pelo menos na agronomia. Nos outros cursos eu não sei. A agronomia, ela tem uma discussão técnica, né? Não tem uma discussão de extensão rural, também (ER 7).

De fato, as instituições de ensino técnico e superior mantêm, de certa forma, um viés produtivista e pouco pautado na participação e na problematização no ensino de extensão rural. De acordo com Scopinho (2010, p. 1), "isto implica ampliar o conceito e o escopo da ação extensionista". E, se a ação extensionista deve ser pautada no diálogo de saberes, as técnicas de ensino-aprendizagem, tradicionalmente utilizadas na academia, também devem passar por modificações, pois segundo a autora, os extensionistas rurais tendem a reproduzir com os agricultores familiares os mesmos métodos que aprenderam com seus mestres.

Callou et al. (2008), avaliando o estado da arte do ensino em extensão rural no Brasil, observaram que as ementas da disciplina de extensão rural ainda privilegiam a difusão tecnológica como prática extensionista, persistindo “uma forte referência ao caráter tecnicista e individualista e não problematizador da disciplina" (p. 105). Os autores afirmam que tem havido um esforço em romper velhos paradigmas, com alguns avanços, mas que muitas dificuldades no campo do ensino da extensão rural ainda permanecem, como a inexistência da discussão sobre temas como "Gênero, Geração e Etnias", tão abordado nas políticas públicas de Ater.

Apesar de seu ingresso recente na extensão rural oficial, oito dos extensionistas entrevistados afirmaram ter pouco ou nenhum conhecimento da Pnater. E sete dos entrevistados afirmaram já ter ouvido falar do princípio de equidade de gênero proposto pela Pnater, mas que nunca foram capacitados ou orientados para o desenvolvimento de trabalhos com este foco.

Caporal \& Ramos (2008) afirmam que, apesar das capacitações realizadas na primeira década deste século, pelo programa de formação de agentes de Ater para atuarem segundo os princípios da Pnater, eles observaram que ainda existe uma certa inércia por parte das instituições e dos extensionistas, que permanecem na prática difusionista, com o uso de metodologias de extensão obsoletas, atualmente ineficientes e inadequadas para as necessidades da nova extensão rural com enfoque agroecológico. Certamente, tal situação ocorre devido ao comportamento organizacional que resiste à mudança do papel difusionista da extensão rural, ainda arraigado nas universidades e nas instituições de Ater. Jalil et al. (2017) observaram que muitas organizações de Ater voltadas para os trabalhos com mulheres ainda estão pautadas nas relações de gênero, dando menor atenção à perspectiva feminista. Dessa forma, a mudança nas estratégias de atuação extensionista nos moldes da Pnater deve partir desde a academia, que formarão os futuros profissionais extensionistas, até as instituições de Ater, onde receberão a formação continuada (Caporal \& Ramos, 2008).

$\mathrm{Na}$ sua trajetória na extensão rural, apenas dois extensionistas afirmaram ter experienciado algum trabalho envolvendo questões de gênero. No entanto, sete deles possuem experiência com políticas públicas que exigem a participação feminina como forma de inclusão da mulher nas relações políticas e econômicas no campo, como a Política Nacional de Alimentação Escolar (PNAE) e o Programa de Aquisição de Alimentos (PAA), nos quais é exigida a cota de $40 \%$ de participação de mulheres no corpo de associados/cooperados das organizações proponentes dos programas. Apenas cinco deles já operaram o Pronaf, mas não possuem experiências com Pronaf Mulher.

Ou seja, os extensionistas não têm se atentado para a orientação de participação feminina nas políticas públicas das quais são mediadores. Não há uma preocupação real quanto às relações de gênero e quanto à inclusão feminina nos espaços político, social e econômico, haja vista a não observância das orientações previstas nas diretrizes dos programas sociais nos quais atuam. Isso demonstra que não basta a exigência legal das ações afirmativas previstas nos programas e políticas. Há a necessidade de se mudar a forma como os extensionistas compreendem seu papel na implementação de políticas públicas e desenvolvem suas ações, buscando-se atualizar e nivelar o conhecimento em extensão rural e em questões de gênero e desigualdades sociais, especialmente sob a ótica feminista.

O conhecimento dos conceitos norteia a orientação e a postura das pessoas diante dos fatos e circunstâncias. A forma como os extensionistas entendem a extensão rural faz com 
que busquem executar sua tarefa da forma mais aproximada possível daquilo que acredita ser sua função. A ideia de gênero e da construção social em que o termo está inserido, contribui para a formação da conduta do extensionista rural diante das relações sociais de gênero. Sabendo-se como implementador de políticas públicas para o meio rural, o extensionista rural estabelece suas estratégias de abordagem e de execução das ações com base nas suas orientações previamente concebidas.

Questionados sobre o conceito de extensão rural, seis dos dez extensionistas entrevistados o definiram como o processo de difusão de tecnologias e assistência técnica ao produtor rural. Para ER 9, a extensão rural continua no mesmo caminho difusionista.

Eu acho que a extensão rural é um encontro de duas ou mais pessoas em que necessariamente um é o acadêmico que detém o conhecimento cientifico. [...] Ele detém o conhecimento cientifico e ele geralmente leva uma proposta de desenvolvimento (ER 7).

Para mim, extensão rural é você conseguir, é você levar algo que não existe lá no meio rural para lá. É o conhecimento seu, acadêmico, cientifico ou prático até aquela propriedade lá (ER 8).

É o trabalho que a gente fazia e continuou fazendo. É a assistência aos agricultores de base familiar, né? (ER 9).

Os outros três afirmaram que a extensão rural não trata meramente da transferência de tecnologias, sendo necessária uma atuação sociocultural dos extensionistas rurais em uma abordagem mais freiriana, considerando que a extensão rural "é um processo educativo" (ER 3), com vistas ao aprendizado mútuo.

Em uma pesquisa realizada por Landini (2014) envolvendo extensionistas rurais de todo o País e suas concepções sobre extensão rural, o autor concluiu que ainda há dificuldades com a atuação grupal e o estabelecimento de parcerias com os agricultores, pois os extensionistas ainda mantêm sua postura difusionista e hierárquica, mesmo quando exercitam metodologias participativas e dialógicas determinadas pela Pnater. O mesmo foi observado neste estudo, pois, para a maioria dos extensionistas rurais, apesar de utilizar metodologias participativas para o desenvolvimento de suas ações, ainda tem uma concepção difusionista_sobre a extensão rural.

Caso se tome como ideia a difusão de tecnologias e de políticas públicas, de mera transmissão de informação como processo para implementação de tais políticas, incorre-se em risco de se permitir a perpetuação do acesso hegemonicamente masculino aos direitos sociais. A desconexão da necessidade de problematização proposta por Freire (1983), do debate e da construção da consciência sobre a realidade proposta por Caporal (2003), reduz a probabilidade de a extensão rural atuar na promoção da inclusão das minorias e dos desfavorecidos historicamente, como é o caso das mulheres.

Recorrendo-se à conceituação do termo gênero, seis dos extensionistas rurais atribuíram às diferenças físico-fisiológicas do que é masculino e feminino e sete não souberam responder o que é divisão sexual do trabalho. Apenas quatro extensionistas apresentaram um conceito aproximado do que significa gênero ou de divisão sexual do trabalho como uma forma de entender as relações de gênero:

Gênero é o fruto das relações entre homem e mulher. [...] O homem faz aquilo que foi determinado pelo conjunto da sociedade e a mulher faz aquilo que foi determinado pela sociedade (ER 7).

Scott et al. (2010) consideram que o termo gênero não explicita, necessariamente, a desigualdades inerentes entre homens e mulheres, mas normas que os modelam, fazendo parte do mecanismo da ordem social e que varia de acordo com as construções dessas identidades na multiplicidade de contextos rurais. Portanto, foi possível verificar que os extensionistas rurais não apenas desconhecem as orientações, princípios e diretrizes da Pnater como também não estão familiarizados com os termos e conceitos empregados na lei. Assim, incorre-se no risco da interpretação do termo gênero empregado nas políticas públicas 
se resumir nas questões das diferenças biológicas entre homens e mulheres e não observar as relações desiguais de poder e consequências sociais dessa desigualdade para o desenvolvimento rural.

\subsection{As relações de gênero no meio rural na visão dos extensionistas}

As relações de gênero sob a ótica extensionista demonstram que, de acordo com o total de respostas apresentadas, os extensionistas rurais entendem que a divisão sexual do trabalho divide também os espaços, sendo o feminino interno ou doméstico/reprodutivo e o masculino externo ou produtivo. Assim, cabe às mulheres rurais as tarefas de cuidados da família, como o preparo de alimentos, o cuidar das crianças e idosos, o cuidado da casa, e também do entorno (jardins, pequenas criações e hortas). Já aos homens é reservada a responsabilidade das atividades principais da propriedade, geradoras de renda, bem como a gestão dos recursos financeiros e o espaço público de relações sociais e econômicas. Outra função atribuída às mulheres pelos entrevistados é a de manutenção da ordem, da harmonia e da união no lar.

Os homens trabalham do lado externo da casa e a mulher trabalha internamente na casa. Mas, geralmente a mulher ajuda nos processos de fora da casa, ela ajuda, ela contribui, né? Mas os homens geralmente não ajudam nas concepções internas da casa, né? Quem cuida do filho, da louça, da horta, dos pequenos animais, na maioria que a gente percebe, são as mulheres. E o homem trabalha na lavoura na atividade econômica que traz mais renda pra família (ER 7).

Ressalta-se que sete dos dez entrevistados afirmaram que as mulheres "ajudam" o marido na condução das atividades agropecuárias e, apesar de utilizarem o termo "ajuda", afirmaram que muitas vezes a mulher trabalha mais do que os homens, pelo próprio acúmulo de jornadas de trabalho. Esta desvalorização da importância do trabalho feminino foi também relatada por Siliprandi (2009) e por Scott et al. (2010), que observaram a representação social dos trabalhos femininos como uma mera condição de "ajuda". Os demais extensionistas utilizaram o termo "contribuição" em vez de "ajuda", e um extensionista usou este último termo ressaltando a ironia na escolha desta palavra, com o intuito de demonstrar a importância do trabalho feminino, que infelizmente não tem o devido reconhecimento pela família.

A participação da mulher está muito restrita a acompanhar o marido nas atividades que já estão condicionadas à família. Então, se ela trabalha, é como uma parceira do marido nas atividades específicas da família. Eu vejo isso na fala deles: "nossa, se minha mulher não estivesse aqui, se eu não tivesse ela me ajudando, me ajudando na propriedade, ajudando [nesse momento o extensionista enfatiza a palavra na entonação de voz], nossa, eu estaria ferrado porque a mão de obra é cara, e, graças a Deus, minha mulher me ajuda muito" (ER 3).

Ela ajuda na roça, ela capina, ela interage na produção econômica das culturas principais. Ela sempre está na lavoura com o homem, ou quando não está na lavoura ela está produzindo comida, está trabalhando no processo de bastidor. Então, ela é uma trabalhadora rural, a própria lei garante isso, né? (ER 7).

Cinco dos dez entrevistados admitiram que, apesar de entenderem a necessidade da desconstrução da divisão sexual do trabalho como forma de dominação masculina, mostraram-se naturalizados com a desigualdade, sendo três deles enfáticos quanto ao papel feminino na divisão de tarefas.

Bom, primeiro a gente não pode abandonar o lado maternal. Então, assim, primeiro no cuidado com os filhos, com a segurança dos filhos, com a criação, o tratamento dos filhos. Fundamental, fundamental! Depois, na segurança do lar, dos cuidados com o lar, da casa etc., no preparo de alimentos etc. (ER 2). 
Não é a mesma [função] do homem. A função dela eu penso que seja muito mais administrativa no sentido de gestão. Ela é a responsável pelo sucesso da família rural hoje. [...] Seria cuidar das atividades que não exijam dela um tempo e uma distância muito grande da casa. Eu acho que é fundamental. [...] Por mais que eu tente não ser machista, a atividade interna da casa é feminina. [...] Porque algumas atividades, a mulher, pelas características físicas, não vou falar de fragilidades, mas pela força que tem que despender, eu acho que a mulher ficaria fora de algumas atividades, entendeu? (ER 3).

Ah, apesar da modernidade de hoje a gente não deixa de ver a mulher como o esteio da família, na parte que se refere à educação, a parte que se refere a carinho, é mais carinhosa, mais organizada, né? Eu tenho aquela visão de a mulher ser mais organizada, ser mais carinhosa, ser mais voltada ao lar. Está mais preocupada com o bem-estar do lar, da família (ER 8).

Quando questionados sobre a participação das mulheres nas políticas públicas implementadas por eles, todos os entrevistados afirmaram que a participação efetiva das mulheres está muito aquém do esperado, ou das cotas estabelecidas. No ponto de vista dos extensionistas, as cotas de participação contribuem para abrir o espaço para a participação feminina, mas tais espaços permanecem sob o domínio masculino, sendo que os homens têm usado o nome de suas esposas para acessar as políticas públicas, como um mero cumprimento às exigências institucionais.

A nossa história de participação feminina tem sido muito frágil. [...] o próprio PAA, por exemplo, ele indica que tem que ter $40 \%$ das mulheres nos projetos, né? Mas isso tem sido usado instrumentalmente, colocam elas lá só pra cobrir a lacuna, não tem um debate, uma discussão muito grande com elas, né? (ER 7).

Observa-se na fala de ER7 o reconhecimento da necessidade de se desenvolver um debate quanto à participação feminina. É evidente que os extensionistas entendem as cotas como uma condicionante da política pública, mas não compreendem ou não relacionaram os propósitos das ações afirmativas que propõem a proporção de participação das mulheres. Ao reconhecer a ausência do debate e, portanto, a necessidade dele, o extensionista explicita a lacuna deixada pela Ater na sua função de problematizar e de questionar a realidade, de envolver os atores no processo participativo e construir novos caminhos a partir dos conhecimentos compartilhados

Para sete dos dez extensionistas entrevistados, o processo decisório intrafamiliar está sob domínio masculino, do "chefe da família". Os outros três acreditam que, de forma indireta, a mulher participa do processo decisório, influenciando o marido.

A decisão, ela está sempre atrelada também à decisão do marido. Eu não tenho percebido muitos casos de mulheres que, salvo aquelas que realmente já moram sozinhas e vivem sozinhas, que dentro de um contexto em que existe a figura do homem, ela toma decisões de forma isolada (ER 2).

Geralmente é do homem, mesmo que as vezes a mulher participe, mas ele jamais vai falar isso. Mesmo que ouça a mulher, né? Mas não é ela que vai lá assinar o contrato, não é ela que vai pegar esse dinheiro (ER 10).

Apesar de reconhecerem o baixo nível de participação feminina nas políticas públicas e da dominação masculina nas relações de gênero, os extensionistas rurais admitem não priorizar ações no âmbito das questões de gênero, reservando-se o papel de implementação da política de forma instrumental, não problematizadora e tampouco dialógica, no tocante às relações de gênero. Isso demonstra uma concepção naturalizada das relações desiguais entre homens e mulheres, levando à inércia dos extensionistas rurais frente à realidade androcêntrica vivida no campo.

De acordo com os estudos de Hernández (2009), os agentes mediadores da extensão rural nem sempre são sensibilizados com as questões de gênero, atuando, na maioria das vezes, como perpetuadores das relações sociais desiguais, em especial as de gênero, devido 
à construção social em que estão inseridos seus valores e vivências. Assim, a atuação extensionista com enfoque em gênero está intimamente relacionada ao seu ponto de vista quanto às relações de poder, especialmente às relações de gênero. A sua atuação é influenciada por essas posições, as quais podem comprometer o acesso de mulheres às políticas públicas e, portanto, a participação e a efetividade da implementação de tais políticas.

Siliprandi (2002) afirma que os mediadores têm dificuldades em incorporar a temática de gênero em suas ações e reconhece que os profissionais de extensão rural fazem parte de uma sociedade machista, sendo um reflexo da mesma. De fato, foi possível observar que nove dos dez extensionistas entrevistados não se consideram preparados para trabalhar políticas de gênero, mas se dispõem a serem capacitados para fazê-lo. Apenas ER 9 se considerou apto para trabalhar com questões de gênero; no entanto, o mesmo extensionista demonstrou uma posição machista da realidade, apresentando a irrevogabilidade da posição doméstica feminina. De acordo com as reflexões de Siliprandi (2002), para uma mudança na conduta dos extesionistas, haveria a necessidade de se desconstruir os preconceitos, tornando horizontal as relações entre homens e mulheres extensionistas e entre estes e os agricultores e agricultoras. Há, portanto, a necessidade de se garantir a formação feminista da equipe executora, de forma sistemática e integrada às ações e metodologias de Ater, tendo como alvo a divisão sexual do trabalho nas relações intrafamiliares no campo (Santos, 2017).

\subsection{O papel das instituições e dos extensionistas no processo de implementação de políticas para mulheres}

Desde os primórdios da extensão rural no Brasil, a ação extensionista foi orientada para a divisão do público, separando as mulheres no espaço doméstico e os "agricultores" (homens, "chefes de família") no espaço produtivo. Olinger (1996) relata a existência da divisão sexual do trabalho tanto na equipe técnica dos extensionistas - mulheres como economistas domésticas e homens como agrônomos - quanto na abordagem às famílias rurais, demonstrando a naturalização nas diferenças de gênero.

A divisão sexual do trabalho se tornou uma norma a ser seguida pela extensão rural, reforçando a naturalização das desigualdades nas relações de gênero na sociedade. Segundo Olinger (1996), apesar do trabalho duro desenvolvido pelas mulheres na agropecuária, os treinamentos e capacitações destinados a elas eram voltados para os afazeres domésticos, ignorando a sua força de trabalho rural ou tornando-o invisível aos olhos institucionais. Assim, o trabalho da extensão rural, historicamente, excluiu as mulheres do acesso aos conhecimentos em tecnologias agropecuárias.

Como forma de mitigar essa dívida social da extensão rural com as mulheres agricultoras, a Pnater se norteia pelos seus princípios de equidade e sustentabilidade, dentre eles, os princípios de equidade de gênero (Brasil, 2010). E, se a própria Pnater reconhece a extensão rural como um processo educativo contínuo, multilateral e multidisciplinar, caberia a ela, então, a inserção do processo de educação em equidade de gênero, de forma continuada, com perspectivas de mudanças de valores no meio rural, contribuindo para efetivar o reconhecimento da mulher rural como cidadã detentora e usufruidora de seus direitos.

Essa proposta foi apresentada pelos extensionistas rurais entrevistados ao serem questionados sobre de que forma a extensão rural poderia contribuir para mudar a realidade do acesso das mulheres rurais às políticas públicas e à Ater. Todos atribuíram parte da responsabilidade da difusão da informação e da educação em relações de gênero à extensão rural, como forma de conscientização das famílias rurais. Além do Estado atuando via extensão rural, os movimentos sociais também foram citados como corresponsáveis nesse processo.

Poderia ser dentro do próprio instituto [a mudança], ou criar um outro mecanismo de ter uma entidade que trabalhe exclusivamente com esse público (ER 1). 
A gente só vai mudar isso no dia que o Estado decidir fazer, trabalhar com extensão rural. [...] No dia em que a gente tiver um Estado comprometido com a extensão rural. O extensionista que já está há 20 anos ou o extensionista que chegar na instituição [...], ele vai entrar sabendo que ele vai trabalhar com extensão rural [...], ele vai estar com um olhar um pouco mais voltado para a família e não como unidade de produção. [...] E, obviamente que as mulheres vão começar a ter uma visibilidade maior. Mas isso é coisa de, no mínimo, médio prazo (ER 3).

A extensão rural se dá a partir do momento em que o governo resolve definir o que que a extensão quer para aquele estado, naquele determinado momento. Se ele constrói uma extensão do modelo que nós atuamos aqui, que é uma extensão, na minha perspectiva, uma extensão machista, só tem homem, né? Masculinizada. [...] Então, nós precisávamos de ter equipes multidisciplinares, inclusive, penso eu, para tratar da saúde da família também. Porque aí pode haver mudança, né? (ER 7)

A extensão rural pode ser um braço pra isso, mas eu acho que ela precisa ter muito mais aula de feminismo pra conseguir fazer isso. Porque talvez, como a extensão rural é um braço do governo para executar as políticas públicas, talvez, nós extensionistas não estamos preparados para trabalhar as questões de gênero com as mulheres. E aí fica difícil. Se a gente não está preparado, até pra gente conseguir articular isso, né? (ER 10)

Observa-se que os extensionistas demonstraram que a mudança depende, também, da vontade política de atender aos princípios da Pnater, capacitando os extensionistas para o trabalho com enfoque em gênero e feminismo. Não apenas reforçando a divisão sexual do trabalho, implementando as políticas de forma a manter as mulheres em atividades "tipicamente femininas", como culinária e artesanato. Assim, na visão dos extensionistas, a atuação de equipes multidisciplinares e a educação dos próprios extensionistas e das famílias rurais em orientações feministas podem contribuir para esse processo. Essa visão corrobora a de Bourdieu (2002), que considera a educação como um dos principais fatores de mudança nas relações de gênero. Segundo ele, a educação contribui para a inserção no mercado de trabalho, gerando independência financeira e consequente transformação das estruturas familiares.

Pettan (2010) analisou o alinhamento das instituições oficiais de Ater com a Pnater, de acordo com a representação dos extensionistas rurais e observou que cerca de $80 \%$ das entidades de Ater trabalham alinhadas à Pnater, mas que as entidades não estão adequadas organizacionalmente para implementar a política. Para Pettan (2010), a Pnater contribuiu para que as organizações consolidassem a missão e visão institucionais e suas estratégias de atuação, priorizando o atendimento aos agricultores familiares e a capacitação do corpo técnico responsável por sua execução local. Reconheceu que as ações estão chegando nas diferentes categorias, mas que, apesar disso, o número de beneficiários das categorias historicamente desfavorecidas ainda é pequeno.

Para a Secretaria de Políticas para as Mulheres (Brasil, 2011), há uma corresponsabilidade dos órgãos governamentais pela consolidação de políticas públicas com enfoque em gênero. A transversalidade seria um dos fatores de sucesso e uma das condições essenciais para seguir avançando. Para tanto, há a necessidade de reorganização da totalidade das políticas públicas e sua assimilação por todas as estruturas governamentais, permitindo uma ação integrada e sustentável, com vistas a garantir o acesso de mulheres às diversas políticas públicas.

A ideia de buscar uma extensão rural plural, respeitando as especificidades de cada região, envolvendo a participação dos diversos atores, rompe com o modelo convencional e exige a quebra de paradigmas. Isso tem colocado em cheque o antigo modelo organizacional das instituições de extensão rural, sendo um processo gradativo e que exige vontade e decisões políticas (Caporal \& Ramos, 2008). Assim, segundo esses autores, para que o processo tenha sucesso é imprescindível "o envolvimento e o engajamento de todos os membros das organizações de Ater de todos os níveis hierárquicos" (p. 8), estimulando a nova prática extensionista no interior das entidades, de forma a democratizar as decisões e incentivar a corresponsabilidade. 
Para Santos (2017), o trabalho com Ater para as mulheres deve ter um enfoque feminista. No entanto, a autora admite que a Ater feminista se depara com o machismo enraizado na sociedade, presente nas organizações sociais do campo, nos sindicatos, nas instituições e nas próprias famílias, dificultando o processo de ruptura das ralações de poder dos homens sobre as mulheres a partir da crítica da divisão sexual do trabalho.

Pettan (2010) esclarece que a mudança ocorre de forma gradativa e depende não somente da institucionalização da Lei de Ater, mas dos diversos atores envolvidos no processo de implementação, como os governos estaduais, os extensionistas rurais, movimentos sociais e sindicais, universidades, organizações não governamentais e os próprios agricultores e agricultoras familiares, dentre outros, que são também corresponsáveis pela efetividade da política, dependendo de seus interesses públicos ou privados, levando-os a colaborar ou não na adoção dos princípios da Pnater.

Os próprios extensionistas reconhecem, portanto, o seu papel como mediador de conflitos e também a necessidade de formação para tal atuação. Alinhando-se as propostas apresentas pelos entrevistados com aquelas apresentadas pelas autoras feministas, a formação feminista deverá ser aplicada desde os níveis hierárquicos superiores das instituições de Ater, buscando-se estabelecer equipes e programas internos de capacitação continuada no tema gênero e feminismo no campo, para que seja possível a sensibilização dos agentes e, a partir dessa sensibilização, a mudança de postura e conduta em sua atuação. Romper com a lógica difusionista e androcêntrica arraigada na extensão rural pode ser o caminho para a tomada de consciência do papel dos extensionistas na contribuição para o processo de mudança e de desenvolvimento rural.

\section{Considerações finais}

A partir dos dados deste estudo foi possível concluir que não houve mudança na conduta dos extensionistas rurais a partir da Pnater. Tal permanência na conduta se deu, provavelmente, pela ineficiência da formação continuada dos extensionistas no sentido de contribuir para romper com os padrões tecnicistas e androcêntricos.

A instituição oficial de Ater, apesar dos investimentos em infraestrutura e capacitações realizadas, também não tem priorizado ações que promovam a redução das desigualdades de gênero, a despeito das orientações da Pnater, bem como as diretrizes de implementação das políticas públicas.

As ações afirmativas que estabeleceram cotas de participação feminina nas políticas públicas não têm contribuído eficazmente para o acesso das mulheres a essas políticas, resultando em mero cumprimento institucional com a comprovação, via assinatura, da participação da mulher, permanecendo o poder de decisão nas mãos dos homens. E que, apesar do conhecimento dos fatos pelos extensionistas rurais, nenhum deles apresentou ações desenvolvidas que minimizem este tipo de atitude ou que estimulem verdadeiramente a participação feminina.

Assim, conclui-se que uma importante limitação para a atuação da Ater nas questões de gênero está intimamente relacionada à visão naturalizada dos extensionistas sobre a condição da mulher rural e sobre as relações desiguais de gênero no campo. O não atendimento à proposta da Pnater de capacitação dos agentes em questões relacionadas às desigualdades de gênero na instituição oficial de Ater no Espírito Santo contribui para a permanência dessa naturalização e postura inerte dos extensionistas frente à realidade do campo.

Romper com esses padrões depende de uma concepção mais crítica sobre o que é o desenvolvimento rural e sobre as relações sociais predominantes. As instituições de Ater podem contribuir com essa mudança de paradigmas para aqueles pautados na liberdade, na igualdade e na agroecologia, buscando o respeito à cidadania e aos direitos dos povos rurais, especialmente daqueles historicamente excluídos do processo. A formação dos extensionistas em Ater feminista pode contribuir para romper com os padrões sociais androcêntricos e hierárquicos, a partir da conscientização crítica dos seus agentes e da utilização de métodos e ferramentas que permitam identificar, problematizar e trazer à 
consciência dos atores sociais sobre as desigualdades de gênero e, assim, fazer o seu papel de mediador no processo de desenvolvimento.

Propõe-se, com este estudo, a mobilização das instituições de Ater, de pesquisa e de ensino, bem como os movimentos sociais, para o debate sobre o status quo dos estudos de gênero e feminismos no estado do Espírito Santo, buscando o nivelar o conhecimento nessa área, como forma de se romper com os entraves que sustentam a naturalização das desigualdades sociais, especialmente as de gênero, raça e classe e a construção de proposições de ações efetivas para a atuação acadêmica e prática da Extensão Rural no campo, baseada nas concepções de uma Ater feminista, bem como intervenções na formulação de políticas públicas que contribuam para a redução das desigualdades de gênero no campo.

Novos estudos que avaliem as mudanças nas diretrizes das instituições de Ater, atrelados à avaliação da atuação extensionista e ao impacto dessas ações na consolidação das políticas públicas com enfoque em gênero no estado do Espírito Santo devem ser realizados, com o intuito de se propor o direcionamento de ações que contribuam para a redução das desigualdades de gênero no meio rural.

\section{Referências}

Bardin, L. (1977). Análise de conteúdo (225 p.). Lisboa: Edições 70.

Beauvoir, S. (1949). O segundo sexo: a experiência vivida (3. ed., Vol. 2, Trad. Sergio Milliet). Rio de Janeiro: Nova Fronteira.

Belotti, E. G. (1987). Educar para a submissão. O descondicionamento da mulher (6. ed., 164 p.). Petrópolis: Vozes.

Bourdieu, P. (2002) A dominação masculina (2. ed., 160 p.) Rio de Janeiro: Bertrand Brasil.

Brasil. (2004). Ministério do Desenvolvimento Agrário - MDA. Política Nacional de Assitência Técnica e Extensão Rural: Desafios Contemporâneos (26p.). Brasília: MDA.

Brasil. (2010, January 12). Institui a Política Nacional de Assistência Técnica e Extensão Rural para a Agricultura Familiar e Reforma Agrária - PNATER e o Programa Nacional de Assistência Técnica e Extensão Rural na Agricultura Familiar e na Reforma Agrária - PRONATER, altera a Lei no 8.666, de 21 de junho de 1993, e dá outras providências (Lei n 12.188, de 11 de Janeiro de 2010). Diário Oficial [da] República Federativa do Brasil, seção 1.

Brasil. (2011). Secretaria de Políticas para as Mulheres - SPM. Orientações estratégicas para institucionalização da temática de gênero nos órgãos governamentais (72 p.). Brasília: Secretaria de Políticas para as Mulheres.

Callou, A. B. F., Pires, M. L. L. S., Leitão, M. R. F. A., \& Santos, M. S. T. (2008). O estado da arte do ensino da extensão rural no Brasil. Revista Extensão Rural, 15(16), 84-115.

Caporal, F. R. (2003). Bases para uma nova ATER Pública. Revista Extensão, 10, 1-20.

Caporal, F. R., \& Ramos, L. F. (2008). Da Extensão Rural convencional à Extensão Rural para o desenvolvimento sustentável: enfrentar desafios para romper a inércia. Recuperado em 13 de março de 2017, de

http://portal.mda.gov.br/dot/rn/clubs/redestematicasdeater/formaodeagentesdeater/contents/pho toflow-view/content-view?object_id=885745

Cintrão, R., \& Siliprandi, E. (2011). O progresso das mulheres rurais. In L. L. Barsted \& J. Pitanguy (Orgs.), O progresso das mulheres no Brasil 2003-2010 (436 p). Brasília: Onu Mulheres.

Coelho, P. S. (2016). A atuação da unidade regional da EMATER de Viçosa-MG: descrição e análise da ATER pública (Dissertação de mestrado). Universidade Federal de Viçosa, Viçosa.

Duarte, D. N. (2010). As diferentes abordagens da ação extensionista e suas implicações para o instituto capixaba de pesquisa, assistência técnica e extensão rural - Incaper (Dissertação de mestrado). Universidade Federal de Viçosa, Viçosa.

Duarte, D. N. (2012). Rede de comercialização, políticas públicas e mudanças na ação extensionista: o caso de Iconha-ES. Revista Extensão Rural, 19(1), 105-136.

Faleiro Barros, T. (2016). Assistência técnica e extensão rural pública no distrito Federal frente à proposta da política nacional de Assistência Técnica e Extensão Rural (Dissertação de Mestrado). Universidade de Brasília, Brasília.

Farah, M. F. S. (2004). Gênero e políticas públicas. Estudos Feministas, 12(1), 47-71. 
Fassio, L. H., \& Castro, L. L. F. (Orgs.). (2006). Instituto Capixaba de Pesquisa, Assistência Técnica e Extensão Rural. Um documento histórico sobre o meio rural capixaba (120р.). Vitória: INCAPER.

Figueiredo, M. A. B. (2010). Una estrategia de desarrollo local desde las experiencias agroecológicas de la región Cañera Pernambucana - Brasil (Tese de doutorado). Departamento de Ciencias Sociales y Humanidades, Universidad de Córdoba, Espanha.

Filipak, A. (2017). Políticas públicas para mulheres rurais no Brasil (2003-2015): análise a partir da percepção de mulheres rurais e de movimentos sociais mistos (Tese de doutorado). Faculdade de Filosofia e Ciências, Universidade Estadual Paulista, Marília.

Freire, P. (1983). Extensão ou comunicação? (7. ed., 93 p.). Rio de Janeiro: Paz e Terra.

Hernández, C. O. (2009). Política de crédito rural com perspectiva de gênero: um meio de "empoderamento" das mulheres rurais? (Tese de doutorado). Universidade Federal do Rio Grande do Sul, Porto Alegre.

Jalil, L. M. (2009). Mulheres e soberania alimentar: a luta para a transformação do meio rural brasileiro (Dissertação de mestrado). Universidade Federal Rural do Rio de Janeiro, Instituto de Ciências Humanas e Sociais, Rio de Janeiro.

Jalil, L. M., Santos, G., \& Ferreira, A. P. (2017). Apresentação: uma construção feita a muitas mãos. In Rede de Ater Agroecológica e Feminista do Nordeste (Org.), ATER mulheres, autonomia e luta: experiências de metodologias feministas (200 p.). Recife: ActionAid.

Korol, C. (2007). Hacia una pedagogía feminista (256 p.). Buenos Aires: El Colectivo, América Libre.

Lamarche, H. (Org.). (1993). A agricultura familiar I: uma realidade multiforme. Campinas: Editora da UNICAMP.

Landini, F. P. (2014). Problemas enfrentados por extensionistas rurais brasileiros e sua relação com suas concepções de extensão rural. Ciência Rural Online, 45(2), 371-377.

Monteiro, D. E. J. (2008). As práticas extensionistas da EMATER-MG sob uma perspectiva de gênero: o caso da Regional de Viçosa-MG (Dissertação de mestrado). Universidade Federal de Viçosa, Viçosa.

Moraes, L. L., Jalil, L. M., Santos, J. H., Costa, M. A. G. \& Oliveira, M. S. L. (2018). Pedagogia Feminista como processo educativo para a reflexão da política pública de ATER no Nordeste. Interritórios, $4(6), 6-31$.

Nunes, S. P., Grígolo, S. C., \& Gnoatto, A. A. (2013). A reorganização dos serviços de ATER no sul do Brasil diante do desenvolvimento capitalista na agricultura. In S. P. Nunes \& S. C. Grígolo (Orgs.), Assistência técnica e extensão rural no sul do Brasil: práticas, avanços e limites metodológicos (200p.). ljuí: Ed. Unijuí.

Olinger, G. (1996). Ascenção e decadência da Extensão Rural no Brasil (523р.). Florianópolis: EPAGRI.

Oliveira, L. R., \& Borges, V. A. J. (Orgs.). (2016). Balanço Social 2015 Incaper (3. ed., 68 p., Documentos, $n^{\circ}$ 244). Vitória: INCAPER.

Oliveira, M. M. (1988). A utopia extensionista: ensaios e notas (314 p.). Brasília: Embrater.

Pacheco, M. E. L. (2009). Os caminhos das mudanças na construção da Agroecologia pelas mulheres. Agriculturas: Experiência em Agroecologia, 6(4), 4-8.

Peixoto, M. (2008). Extensão Rural no Brasil: uma abordagem histórica da legislação (Textos para Discussão, n²4). Brasília: Senado Federal.

Pettan, K. B. (2010). A Política Nacional de Assistência Técnica e Extensão Rural (PNATER): percepções e tendências. (Tese de doutorado). Universidade Estadual de Campinas, Campinas.

Piscitelli, A. (2009). Gênero: a história de um conceito. In H. B. Almeida, \&J. E. Szwako (Orgs.), Diferenças, igualdade (pp. 116-149). São Paulo: Berlendis E Vertecchia.

Rodrigues, C. M. (1997). Conceito de seletividade de políticas públicas e sua aplicação no contexto da política de Extensão Rural no Brasil. Cadernos de Ciência \& Tecnologia, 14(1), 113-154.

Santos, G. (2017). Um olhar feminista de ATER: a experiência da Casa da Mulher do Nordeste no Pajeú. In Rede de Ater Agroecológica e Feminista do Nordeste (Orgs.), ATER Mulheres, Autonomia e luta: experiências de metodologias feministas (200 p.). Recife: ActionAid.

Scopinho, R. A. (2010, dezembro 1-3). Diálogo de saberes: experiências inovadoras no ensino da Extensão Rural. In Anais do $2^{\circ}$ Seminário Nacional de Ensino em Extensão Rural. Santa Maria: UFSM. Recuperado em 13 de março de 2017, de http://w3.ufsm.br/seminarioextensaorural/arqs/Scopinho_R_A.pdf

Scott, J. W. (2008). Género e historia (337 p.). México: Universidade Autónoma de la Ciudad de México. 
Scott, P., Rodrigues, A. C., \& Saraiva, J. C. (2010). Onde mal se ouvem os gritos de socorro: notas sobre a violência contra a mulher em contextos rurais. In P. Scott, R. Cordeiro, \& M. Menezes (Orgs.), Gênero e geração em contextos rurais. Ilha de Santa Catarina: Ed. Mulheres.

Siliprandi, E. (2002). O que se pensa, o que se faz, o que se diz: discursos sobre as mulheres rurais. Educação em Debate, 2(44), 106-110.

Siliprandi, E. (2009). Mulheres e agroecologia: a construção de novos sujeitos políticos na agricultura (Tese de doutorado). Centro de Desenvolvimento Sustentável, Universidade de Brasília, Brasília.

Siliprandi, E. (2015). Mulheres e agroecologia: transformando o campo, as florestas e as pessoas (352 p.). Rio de Janeiro: Editora UFRJ.

Siliprandi, E., \& Cintrão, R. (2015). Mulheres rurais e políticas públicas no Brasil: abrindo espaços para o seu reconhecimento como cidadãs. In C. Grisa, \& S. Schneider (Orgs.), Políticas públicas de desenvolvimento rural no Brasil (624 p.). Porto Alegre: Editora da UFRGS.

Villwock, A. P. S., Germani, A. R. M., \& Roncato, P. E. S. (2016). Questões de gênero no mundo rural e na extensão rural brasileira. Revista Alamedas, 4(1), 1-17.

Wanderley, M. N. B. (2001). A ruralidade no Brasil moderno. Por um pacto social pelo desenvolvimento rural. In N. Giarracca. ¿Una nueva ruralidad en América Latina? Buenos Aires: Consejo Latinoamericano de Ciencias Sociales.

Data de submissão: 14 de novembro de 2017

Data de aceite: 28 de outubro de 2018.

Classificação JEL: Q16 